\author{
Michał Masłowski (D) https://orcid.org/0000-0001-6432-7641 \\ Uniwersytet Paryski - Sorbona \\ michel.maslowski2@gmail.com
}

\title{
Tożsamość w Europie Środkowej
}

\section{Identity in Central Europe}

\begin{abstract}
The notions of Central Europe and East-Central Europe (in opposition to Naumann's Mitteleuropa), as well as Europe médiane, have replaced after the fall of Communism the term Eastern Europe, which was in universal use since the war. The metaphors offered by Miłosz, Kundera, and Braudel inspired the studious historical works of Halecki, Kłoczowski, Wandycz, Bibó and Szűcs, and Snyder, which, in turn, have revealed from their longue durée point of view a cohesiveness in the structures and identities of nations situated "between Germany and Russia;" the three historical kingdoms of Bohemia, Hungary, and the Polish-Lithuanian Commonwealth. The distinctive identity of this region was expressed in the nineteenth century under the influence of Herder's philosophy and Romantic poetry, by the figure of a "national poet" and the idea of "cultural nationhood," which was distinct from the "nation state" associated with the Enlightenment paradigm. National "culture canons" and the "paradigmatic" type of identity of these countries were the result of specific cultural patterns. Meanwhile, a positional ("syntagmatic") type of identity prevailed in bourgeois Western states. The transformation of countries after the fall of Communism, the political liberalization and pluralization of opinion, as well as the lack of a clear identity discourse in the West, have to some extent inspired the evolution towards politics of memory - an affirmation of the "paradigmatic" identity, which is not necessarily well suited for the conditions of modernity.
\end{abstract}

Keywords: Central Europe, East-Central Europe, Europe médiane, cultural canon, identity, civilization, national poet, cultural nationhood, intelligentsia, essentialism, processualism, universality, Bohemia, Hungary, Poland

Streszczenie: Terminy Europy Środkowej, Europy Środkowo-Wschodniej (w opozycji do Mitteleuropa Friedricha Naumana), jak też Europy Pośredniej (médiane), zastąpiły po upadku komunizmu używany na świecie od wojny termin Europy Wschodniej. Metafory Czesława Miłosza, Milana Kundery i Fernanda Braudela dały impuls do poważnych prac historycznych Oskara Haleckiego, Jerzego Kłoczowskiego, Piotra Wandycza oraz Istvána Bibó i Jenő Szűcsa, jak też Timothy’ego Snydera, które ukazały w perspektywie „długiego trwania” jedność strukturalną i tożsamościową narodów „pomiędzy Niemcami i Rosją”, trzech królestw historycznych Czech, Węgier i Rzeczpospolitej Obojga Narodów. Oryginalny typ tożsamości regionu skrystalizował się w XIX wieku pod wpływem filozofii Herdera 
i poezji romantycznej, poprzez figurę „poety narodowego” oraz typ „narodu kulturowego”, odrębny od „państw narodowych” pozostających pod wpływem paradygmatu Oświecenia. „Kanony kultury” narodowej i typ tożsamości „paradygmatycznej” tych krajów związany był ze wzorami kulturowymi. Typ tożsamości pozycyjnej („syntagmatycznej”) dominował natomiast w mieszczańskich krajach Zachodu. Przemiany krajów po upadku komunizmu, liberalizacji ustrojowej i pluralizacji opinii oraz braku jasnego dyskursu tożsamościowego Zachodu ewoluowały częściowo w stronę polityki historycznej - afirmacji tożsamości „paradygmatycznej”, niekoniecznie zaadaptowanej do warunków nowoczesności.

Słowa kluczowe: Europa Środkowa, Europa Środkowo-Wschodnia, Europa Pośrednia (médiane), kanon kultury, tożsamość, cywilizacja, poeta narodowy, naród kulturowy, inteligencja, esencjalizm, procesualność, uniwersalność, Czechy, Węgry, Polska

O ile na Zachodzie czy w Stanach Zjednoczonych spory o zasadność nazwy wydają się rozstrzygnięte, o tyle w Polsce ciągle trwają. Czy naprawdę w latach osiemdziesiątych, w bojach o Europę Środkową chodziło tylko o emancypację w stosunku do Związku Radzieckiego, o „finlandyzację”, czy też istotnie w okresie nie tylko 45 lat trwania „realnego socjalizmu”, ale i w perspektywie „długiego trwania”, kraje „pomiędzy Rosją i Niemcami” łączyły pewne cechy strukturalne, wzmocnione w okresie romantyzmu i XIX-wiecznych walk o wolność i kulturę? Czy na przykład Polska jest naprawdę inna od reszty świata, niezrozumiała dla nie-Lechity, czy też wręcz przeciwnie - jej tożsamość można wyjaśniać kontekstem geokulturowym? „Boje” miały przede wszystkim charakter polityczno-historyczny, ale dotyczyły w istocie pamięci i tożsamości cywilizacyjnej, a więc kultury w szerokim sensie.

Ze względu na istniejące już publikacje ${ }^{1}$, przypomnijmy tylko rudymenty: oboczność terminów uznanych na Zachodzie dzięki słynnemu artykułowi Milana Kundery Zachód porwany albo tragedia Europy Srodkowej i książce Czesława Miłosza Rodzinna Europa odwołuje się do pewnej wspólnoty losu historycznego dawnych potęg regionalnych, które potem zniknęły z mapy politycznej, ale też niebezpiecznie kojarzy się z pojęciem Mitteleuropa Friedricha Naumana z 1915 roku - podstawy polityki pangermańskiej Niemiec. By się jej sprzeciwić, historyk polski Oskar Halecki wylansował w Ameryce podczas

1 Por. między innymi mój artykuł „Inna Europa”, „Europa porwana”, Europa Środkowo-Wschodnia... Tożsamość kulturowa i paradygmat romantyczny, tłum. M. Nicińska, „Przegląd Filozoficzno-Literacki” 2013, nr 1-2, zeszyt monograficzny: Modernizm(y) Europy Środkowo-Wschodniej, s. 115-136. Tamże bibliografia.

2 M. Kundera, Zachód porwany albo tragedia Europy Środkowej, tłum. M.L., „Zeszyty Literackie" 1984, nr 5.

3 C. Miłosz, Rodzinna Europa, Paryż 1959; przetłumaczona na francuski jako Une autre Europe; nazwa L'Autre Europe używana była następnie przez ponad dwadzieścia lat dla określenia całego regionu. 
drugiej wojny światowej termin Europa Środkowo-Wschodnia ${ }^{4}$, podjęty następnie przez historyków niemieckich, polskich i węgierskich.

W pojęciu Europy Środkowej, obecnie najpopularniejszym na świecie, nazewnictwo geograficzne nałożyło się na historię i ideologię, jak też na kultury $\mathrm{i}$ ich interferencje z cywilizacjami... Metafory pisarzy okazały się dla wyobrażeń antropologicznych płodniejsze niż koncepcje polityczne. W swym artykule Kundera tłumaczył: „geograficznie Europa Środkowa jest środkiem, kulturalnie - Zachodem, a politycznie - od 1945 roku - Wschodem"s. Po upadku komunizmu i zburzeniu muru berlińskiego Kundera nigdy nie chciał się zgodzić na przedruk eseju, ale w późniejszych publikacjach mówił raczej o „małych narodach”, nie tyle ze względu na ich geograficzną rozległość, co na sytuację: „przeznaczenie (...); zawsze spotykały się z obcesową ignorancją ze strony wielkich $\mathrm{i}$ ich istnienie jest wiecznie zagrożone i podawane w wątpliwość; albowiem ich istnienie jest wątpliwością" ${ }^{\circ}$. Postara się też tłumaczyć jedność narodów regionu zachowujących się jak rodziny, gdyż bogactwo wydarzeń kulturalnych jest tu „na miarę ludzką": „mały naród podobny jest do wielkiej rodziny i tak właśnie lubi siebie określać”" Rozwinie jednak ten termin później: „Jedność nie leżała w ich zamiarze. Były sobie bliskie nie z wyboru, nie z sympatii, nie ze względu na lingwistyczną wspólnotę, lecz z powodu zbliżonych doświadczeń, wspólnych sytuacji dziejowych, które je łączyły w różnych okresach, w różnych konfiguracjach i w ruchomych, nigdy nie ostatecznych granicach".

Skrót metaforyczny Kundery jest uderzający i przemawia do wyobraźni, ale ujmuje w nawias tysiąc lat historii krajów, ich „złoty wiek” poprzedzający klęski, kiedy za Karola IV Praga była trzecim miastem Europy, Mattias Korwin tworzył w XV wieku z Węgier potęgę regionalną, a polsko-litewska Rzeczpospolita Obojga Narodów stała się w XVI-XVII wieku największym terytorium europejskim. Pomija też próby zjednoczenia politycznego Europy Środkowej przez Korwina, Jagiellonów, zanim Habsburgowie podporządkowali sobie kraje Dunaju, a potem podzielili się Polską z Rosją i Prusami. To dopiero wtedy te „państwa historyczne” (określenie Friedricha Engelsa) stały się „małymi narodami”. Kluczem jest wspólnota losu.

Rdzeniem Europy Środkowej są narody należące do królestw historycznych Czech, Węgier i Polski, a więc Litwini, Białorusini, Ukraińcy, Chorwaci,

4 O. Halecki, East Central Europe in Postwar Organization, Philadelphia 1943; tenże, The Borderlands of Western Civilization. A History of East Central Europe, New York 1952.

5 M. Kundera, Zachód porwany albo tragedia Europy Środkowej, dz. cyt., s. 15.

6 Tenże, Zdradzone testamenty, tłum. M. Bieńczyk, Warszawa 1996, s. 172. Wersja oryginalna: tenże, Les testaments trahis, Paris 1993, s. 224 [wyróżn. M.M.].

7 Tenże, Zdradzone testamenty, dz. cyt., s. 173 [wyróżn. M.M].

8 Tenże, Zastona. Esej w siedmiu częściach, tłum. M. Bieńczyk, Warszawa 2006, s. 59. Wersja oryginalna: tenże, Le Rideau, Paris 2005. 
Rumuni (zwłaszcza ci z Siedmiogrodu) ${ }^{9}$. Wszystkie one przeszły przez okres opresji - okupacji sowieckiej, i wszystkie dążyły ku Zachodowi.

Metafory Kundery i Miłosza, do których dołączył dysydent czeski Josef Kroutvor (znany również jako „Josef K.”) ${ }^{10}$, były też rozpracowywane przez historyków. Najważniejsze z nich to prace Istvána Bibó i jego ucznia Jenő Szűcsa $\left(\operatorname{Trzy}\right.$ Europy, $\left.1983^{11}\right)$. Ta ostatnia książka z przedmową, a więc akceptacją Fernanda Braudela, współtwórcy szkoły historycznej Annales, spełniła szczególną funkcję. Autor przedstawia w niej bowiem paradygmat kształtowania historycznego Europy Zachodniej (od czasów Karola Wielkiego w IX wieku), Europy Środkowo-Wschodniej (w X-XII wieku) i wreszcie Europy Wschodniej, to znaczy Rosji (od XVI wieku). Schematycznie ujmując: o ile dwie pierwsze Europy rozwijały się zgodnie z modelem feudalnym i zasadą rozdziału Kościoła od państwa, jak też podwójnej struktury władzy - królewskiej i obywatelskiej („stany”), i nawet jeśli proces ten pozostał niezakończony w „drugiej” Europie Środkowo-Wschodniej, to w Europie Wschodniej nie dokonał się rozdział władzy religijnej od świeckiej, co wprowadziło zasadę autokracji uniemożliwiającą rozwój społeczeństwa obywatelskiego. Te różnice pomiędzy „trzema Europami" trwają nadal w świadomościach, obyczajach politycznych i modelach zachowań. We Francji nazwa Europy Środkowej rozpowszechniła się dzięki publikacji Atlas des peuples d'Europe centrale, André i Jeana Selliera (1991), oraz dzięki wielu innym autorom używającym tej nazwy ${ }^{12}$.

Braudel użył we Wstępie do książki Szücsa terminu Europy „pośredniej” (médiane), podjętego następnie przez geografów i historyków, zwłaszcza przez Michela Fouchera ${ }^{13}$, jak też później Antoine’a Marèsa ${ }^{14}$. Mamy więc szkatułkowy charakter konceptów: Europa - Europa pośrednia (médiane) - Europa

9 Por. T. Snyder, The Reconstruction of Nations: Poland, Ukraine, Lithuania, Belarus, 15691999, New Haven 2003; tłum. pol.: tenże, Rekonstrukcja narodów. Polska, Ukraina, Litwa, Biatoruś 1569-1999, tłum. M. Pietrzak-Merta, Sejny 2006.

10 J. Kroutvor, Europa Środkowa: anegdota i historia, tłum. J. Stachowski, Izabelin 1998.

11 J. Szűcs, Trzy Europy, wstęp F. Braudel, tłum. J.M. Kłoczowski, Lublin 1995.

12 A. i J. Sellier, Atlas des peuples d'Europe centrale, Paris 1991. Por. P.R. Magocsi, Historical Atlas of East Central Europe, wyd. 1, Seattle 1993; Histoire des idées politiques en Europe centrale, red. Ch. Delsol, M. Masłowski, Paris 1998; Mythes et symboles politiques en Europe Centrale, red. Ch. Delsol, M. Masłowski, J. Nowicki, Paris 2002; Dissidences, red. Ch. Delsol, M. Masłowski, J. Nowicki, Paris 2005; X. Galmiche, Villes multiculturelles en Europe centrale. Lieux communs de la multiculturalité urbaine en Europe centrale, „Cultures d'Europe centrale” 2009, nr 8; X. Galmiche, Europa pachnaca partykularyzmem? Nowe Abdery w Europie Środkowej albo przyzwolenie na pospolitość, tłum. M. Chmurski, „Przegląd Filozoficzno-Literacki” 2011, nr 2, zeszyt monograficzny: Modernizm(y) Europy Środkowej, red. E. Paczoska, M. Chmurski, s. 137-165.

13 Fragments d'Europe. Atlas de l'Europe Médiane et Orientale, 260 map, red. M. Foucher, Paris 1993.

14 Bohemisty, twórcy wraz z Marie-Élizabeth Ducreux grupy badawczej GDR zajmującej się Europą pośrednią (médiane). 
Środkowa. Ten ostatni termin jest najsilniej nacechowany antropologicznie dzięki przeważającemu znaczeniu paradygmatu kulturowego tożsamości.

Skądinąd koncept trzech Europ Szűcsa należy skojarzyć z książką często dyskutowaną, o stałej aktualności: Samuela P. Huntingtona Zderzenie cywili$z a c j i^{15}$. Nie wchodząc w polemiki dotyczące trwałości cech kulturowych, sam koncept cywilizacji używany już przez Braudela wydaje się niezwykle użyteczny dla zrozumienia różnic między wielkimi strefami kulturowymi świata i - by nawiązać do naszego tematu - rozróżnienia między cywilizacjami zachodnią i bizantyjską. Odpowiada ono bowiem, zgodnie z paradygmatem Szűcsa różnicom strukturalnym pomiędzy Europą Zachodnią i Środkowo-Wschodnią z jednej, a Wschodnią z drugiej strony. Podobnie stwierdza z naciskiem Kundera w odniesieniu do popularnego na Zachodzie stereotypu „duszy słowiańskiej”: nie ma „żadnej słowiańskiej kultury, żadnego słowiańskiego świata (...) nic wspólnego z Rosją" ${ }^{16}$.

Następnie pojawiły się opracowania historyczne podejmujące burzliwe dzieje Europy Środkowej, zwłaszcza Jerzego Kłoczowskiego i Piotra Wandycza ${ }^{17}$. Ten ostatni podkreślił podwójne dziedzictwo regionu - monarchii Habsburgów i Rzeczpospolitej Obojga Narodów - republiki szlacheckiej, która wypracowała oryginalne formy życia politycznego i zachowań obywatelskich. Historyk idei Andrzej Walicki porównał z kolei paradygmaty tożsamości Polaków z najbardziej znanymi teoriami narodu ${ }^{18}$. Wyraźnie wyodrębnił „szlachecki republikanizm” oświecenia i „ideologię narodową” Tadeusza Kościuszki od mesjanizmów romantycznych i późniejszego „integralnego nacjonalizmu”. Tezy jego są kontrowersyjne z różnych punktów widzenia, zbyt może rozdzielają epoki pomimo ciągłości pamięci zbiorowej, ale pozwalają podejść do sprawy tożsamości analitycznie jak u żadnego innego myśliciela.

Pamięć przeszłości posłużyła narodom w sytuacji braku instytucji politycznych do wypracowania w XIX wieku modelu tożsamości przez kulturę.

Przypomnijmy, że „długi XIX wiek” przemienił obraz i naturę narodu: z terytorialnego stał się wspólnotowy, co wyrażają hymny: „Jeszcze Polska nie zginęła, kiedy my żyjemy”; werset został przejęty w hymnie ukraińskim i w znanej

15 S.P. Huntington, Zderzenie cywilizacji i nowy ksztatt tadu światowego, tłum. H. Jankowska, Poznań 2018 (oryg.: The Clash of Civilizations, 1996).

16 M. Kundera, Zastona, dz. cyt., s. 57; por. A. Finkelkraut, L'ingratitude: conversation sur notre temps, Paris 1999, s. 31-32.

17 J. Kłoczowski, Mtodsza Europa. Europa Środkowo-Wschodnia w kregu cywilizacji chrześcijańskiej średniowiecza, Warszawa 1998; P.S. Wandycz, The Price of Freedom. A History of East Central Europe from the Middle Age to the Present, London--New York 1992; thum. pol.: tenże, Cena wolności. Historia Europy Środkowo-Wschodniej od średniowiecza do wspótczesności, tłum. T. Wyrozumski, Kraków 1995.

18 A. Walicki, Philosophy and Romantic Nationalism. The Case of Poland, Notre Dame 1994; tenże, Polskie ideologie narodowe w perspektywie typologiczno-porównawczej [w:] tegoż, Naród, nacjonalizm, patriotyzm, Kraków 2009. 
pieśni chorwackiej, narodowym „hymnie bis”. Hymny czeski, słowacki i węgierski są bardziej tradycyjne, ale również ukazują wspólnotę w ruchu: czeski „Gdzie jest dom mój?” (Kde domov můj?), słowacki „Nad Tatrami się błyska” (Nad Tatrou sa blýska, ze skojarzeniem terytorialnym jednak) czy węgierski modlitwa Ferenca Kölcseyego „Boże zbaw Węgrów” (Isten, áldd meg a magyart), znana również jako $Z$ burzliwych wieków węierskiego ludu. Niektórzy historycy mówią o „ontologii narodu” czy jego „transcendentalizacji” (Andreas Lawaty).

Instytucja „poety narodowego" (wieszcza), zjawisko nieznane w krajach „pierwszego” Zachodu, też mogłaby zostać uznana jako cecha wyróżniająca narody Europy Środkowej. Otóż, jak wszyscy wiedzą, Adam Mickiewicz jest „poetą narodowym” Polaków, Taras Szewczenko Ukrańców, Sandőr Petőfi i Mihalý Vörösmarty Węgrów, Hynek Mácha - Czechów (choć intelektualiści i naukowcy jak František Palacký, Josef Jungmann czy Josef Dobrovský są równie ważni dla rozbudzenia narodowego). Istnieją również poeci narodowi słowaccy, tacy jak L’udovit Štúr, i późniejsi poeci romantyczni rumuńscy (na przykład Mihai Eminescu), białoruscy (Janko Kupala), litewscy (Maironis), a także słoweńscy (France Prešeren).

Jednym słowem romantyzm stworzył w Europie Środkowej raczej paradygmat „narodu kulturowego” niż państwa narodowego opartego na oświeceniowym paradygmacie racjonalizmu ${ }^{19}$. Jest powszechnie wiadome, że literatura i poeci odegrali tu rolę niezmiernie ważną, podobnie jak kompozytorzy: Fryderyk Chopin czy Stanisław Moniuszko dla Polaków, Antonín Dvořák, Leoš Janáček czy Bedřich Smetana dla Czechów, Franz Liszt i później Béla Bartók dla Węgrów, Mikalojus Konstantinas Čiurlionis dla Litwinów. Nie można też zapominać o instytucjach kulturowych; teatry, filharmonie, muzea literackie to właściwe dla każdego kraju istotne odniesienie tożsamości.

Zjawiska znane $\mathrm{z}$ historii kultury polskiej mają swoje odpowiedniki w innych krajach regionu. Po wielkich romantykach powstało malarstwo ilustrujące przeszłość i powieść historyczna. W Polsce to oczywiście Trylogia, w Czechach Alois Jirásek z wielką metaforą opresji austriackiej, jaką była słynna powieść Temno [Ciemności], która odegrała rolę analogiczną do dzieł Sienkiewicza. Na Węgrzech najbardziej znanym powieściopisarzem historycznym stał się Mór Jókai. Na Słowacji, w okresie konsolidacji języka literackiego, również powstały dzieła afirmacji tożsamościowej (Ján Kalinčiak, Pavol Országh Hviezdoslav).

Proces kodyfikacji pamięci historycznej oraz krystalizacji kanonu literackiego i kulturowego zakorzeniony był w formacji nowej warstwy społecznej - inteligencji. Jak wiadomo, chodziło o utworzoną w XIX wieku „klasę” ludzi żyjących z pracy umysłowej - nauczycieli, artystów, lekarzy, inżynierów, czasem administratorów państwowych. W Polsce czy na Węgrzech była to głównie

19 Po francusku oddaję to opozycją: peuple-nation vs. Etat-nation. W teorii Friedricha Meineckego opozycja ta przybiera postać: Kulturnation vs. Staatsnation. Por. F. Meinecke, Weltbürgertum und Nationalstaat: Studien zur Genesis des deutschen Nationalstaates, München 1911. 
spauperyzowana szlachta, w Czechach zwłaszcza mieszczaństwo, a na Ukrainie czy na Słowacji chodziło zasadniczo o chłopów ${ }^{20}$.

Dla nas ważny jest specyficzny etos tej warstwy społecznej niosącej misję prowadzenia narodu ku światłu, formowania zachowań i - w sytuacji podległości politycznej - ochrony kultury narodowej i jej odnawiania, jak w przypadku budzicieli czeskich (České národni obrozeni). Tak uformowany inteligent bardzo się różnił od typowego intelektualisty francuskiego, który był „adwokatem zasad uniwersalnych w określonym kraju"21.

Zostawmy teraz na boku różne teorie formowania się nowoczesnego narodu, skonfrontowane z doświadczeniem polskim przez Andrzeja Walickiego. Zauważmy natomiast, że powstałe w wyniku tych procesów „miejsca pamięci” symbolizowały specyficzną tożsamośc „narodu kulturowego”, z silną interakcją pomiędzy świadomością indywidualną i zbiorową ${ }^{22}$.

Naród w rozumieniu tym nie ma charakteru esencjalistycznego (naród jako osoba, co doprowadzi do „teologii narodu”), ale ewolucyjny i procesualny. I jednocześnie w jakiś sposób posiada egzystencję ontologiczną, gdyż bez niego nie ma ani jednostki, ani twórczości dziejowej, ani uniwersalności. Norwid to odczuł: „Naród że cierpi, więc nie jest ideją,/ Lecz jest wcieleniem żywym, organicznym,/ Istotą rzeczy" (Niewola ${ }^{23}$ ). Uniwersalność nie ma zatem charakteru abstrakcyjnego, ale wynika z doświadczeń partykularnych. Tożsamość schroniła się w kulturze, która odgrywała rolę zarówno sejmu, sądu co w pewnym sensie Kościoła, który w Polsce jako instytucja podtrzymywał tę ewolucję. Skrystalizowała się wówczas tożsamość zbiorowa typu ipse, duchowość, rodzaj jaźni narodu, która pozwalała na afirmację kulturową mimo nieistnienia politycznego.

Oczywiście sytuacja była inna w różnych krajach regionu, zwłaszcza po ugodzie w 1867 roku i powstaniu podwójnej monarchii Austro-Węgier. Ale nawet w Czechach, najsilniej zmarginalizowanych politycznie, powstała świadomość, jak to wyraził twórca przyszłej Czechosłowacji Tomáš G. Masaryk: „naród, duch narodowy wyrażają się (...) w literaturze. (...) Sztuki plastyczne są również (...) wyrazem narodowości, ale można powiedzieć to samo o religii, o prawach i obyczajach, o pracy (...), które zmieniają się w każdym narodzie"24.

20 Dzieje inteligencji polskiej do roku 1918, red. J. Jedlicki, t. 2: J. Jedlicki, Btędne koto 1832-1864, Warszawa 2008.

21 A. Finkelkraut, dz. cyt., s. 55.

22 S. Brzozowski, Idee, Kraków 1990, s. 435 i 447. Jeśli chodzi o „miejsca pamięci”, warto zwrócić uwagę też na znaczenie ponadnarodowe takich miejsc (na przykład polsko-niemieckie, jak Gdańsk, albo polsko-węgierskie i węgiersko-słowackie, jak Bratysława/Pressburg/Prešporok/ Pozsony - „lieux de mémoire”), wskazujących na podobieństwa konstrukcji tożsamościowych.

23 C.K. Norwid, Niewola [w:] tegoż, Pisma wszystkie, wyd. J.W. Gomulicki, Warszawa 1970-1971, t. 3, s. 384.

24 T.G. Masaryk, La Nouvelle Europe, Paris 2002, s. 62 [tłum. M.M.]. 
W drugiej połowie XIX wieku skrystalizował się w tych krajach - równolegle do formowania się warstwy inteligencji - kanon kultury ${ }^{25}$, który wciąż funkcjonuje, nawet jeśli jest stale kontestowany i dyskutowany.

Odrodzenie „małych narodów” Europy Środkowej w 1918 roku miałoby wszelkie cechy cudu, gdyby nie poprzedził go wiek powstań polskich i węgierskich, afirmacji kulturowej i wysiłków, by odzyskać suwerenność. Roman Szporluk, badacz amerykańsko-ukraiński, porównuje wagę tych wysiłków do znaczenia rewolucji francuskiej, gdyż ostatecznie przemodelowały mapę Europy ${ }^{26}$. Afirmacja kulturowa narodów kulturowych przyniosła więc owoce polityczne.

Co do tożsamości indywidualnej dwa typy przeważały w Europie: w społeczeństwach mieszczańskich i kupieckich Zachodu dominowała tożsamość „pozycyjna” czy „syntagmatyczna”, gdyż pozycja społeczna i ekonomiczna decydowała, „kim się jest”; a tożsamość „paradygmatyczna” była silna w Europie Środkowej, gdzie wcielenie modeli kulturowych zachowań i wzorów bohaterstwa wydawało się najważniejsze.

Jeśli wyjść ze schematu zarysowanego przez Paula Ricœura, rozróżniającego tożsamość typu idem, zewnętrzną i formalną, od tożsamości ipse, która jest $\mathrm{w}$ istocie narracją o sobie, opowiedzianą samemu sobie i weryfikowaną ustawicznie, trzeba przyznać, za filozofem francuskim, że zasada ta może być stosowana nie tylko do jednostek, ale i do narodów: „Można mówić o tożsamości ipse wspólnoty (...): jednostka i wspólnota konstytuując się w swej tożsamości, otrzymują takie opowieści, które stają się dla jednych i dla drugich ich rzeczywistą historią". Dalej Ricœur precyzuje siłę tożsamości narracyjnej jako energii przekształcającej tożsamość w czyn, „który powoduje, że odpowiedzialność etyczna staje się najważniejszym czynnikiem tożsamości ipse”27.

W wypadku tożsamości typu pozycyjnego (syntagmatycznej) kryteria i składniki opowieści były porównywalne, gdyż zdeterminowane przez schematy społeczne bogactwa, kariery zawodowej, przynależności do środowisk władzy. W przypadku tożsamości paradygmatycznej rozpoznanie i uznanie zależały od modeli kulturowych grupy społecznej czy narodu rozumianego - w teorii Antoniny Kłoskowskiej - jako „całość tekstów kultury narodowej, symboli i wartości tworzących świat tej kultury”. „Tożsamość narodowa i przyswojenie kultury (valence) decydowały następnie o odniesieniach tożsamości”28.

25 A. Kłoskowska, Kultury narodowe u korzeni, Warszawa 1996. Por. Culture et identité en Europe centrale. Canons littéraires et visions de l'histoire, red. M. Masłowski, D. Francfort, P. Gradvohl, Paryż-Brno 2011.

26 R. Szporluk, Communism and Nationalism. Karl Marx versus Friedrich List, New YorkOxford 1988, s. 84-85.

27 P. Ricœur, Temps et récit, t. 3, Paris 1985, s. 356, 359 (wyd. pol.: tenże, Pamięć, historia, zapomnienie, tłum. J. Margański, Kraków 2006; tłum. pol. nie zawiera przywoływanych tu konkluzji).

28 A. Kłoskowska, dz. cyt., s. 110-112. 
Indywidualnie podporządkowywano się wtedy modelowi kanonicznemu każdej kultury, a wspólnotowo horyzontowi oczekiwań historiozoficznych, etycznych i duchowych każdej z nich, gdyż dopiero na tym poziomie można odnaleźć Sens usprawiedliwiający życie, poświęcenie i zaangażowanie (dar z siebie). Porównywanie jest wtedy trudne, wręcz niemożliwe, gdyż rozróżnienia są typu jakościowego, a nie ilościowego (jak w wypadku tożsamości syntagmatycznej). Na to również skierowane są dzisiaj krytyki pojęcia „charakteru narodowego” (czy „misji”), oskarżenia o esencjalizm i o nacjonalizm szowinistyczny. Ale wszystko zależy od sposobu zastosowania tych kryteriów. Jeśli uczciwie zrewidować swe życie indywidualne i narodowe jako narrację albo dyskurs, nie ma esencjalistycznego zamykania się w sobie i można zaakceptować odmienność od innych jako „koncert narodów” (Johann Herder, Adam Mickiewicz). W tej perspektywie każdy ma swoje zadanie (czy misję) i uznaje osąd owoców swych czynów.

W perspektywie tożsamości syntagmatycznej charakter kultur (wojowniczy, kupiecki czy rolniczy) okazuje się jakoś równowartościowy, gdyż chodzi o różne modele wewnątrz tego samego typu; doskonałość wojownika, kupca (mieszczanina) czy chłopa (rolnika) będzie równie akceptowalna wspólnotowo i odpowiednio skodyfikowana symbolicznie. Wedle tych kryteriów bohaterstwo powstańcze typowo polskie, węgierskie czy też ukraińskie, pomimo różnic odniesień „klasowych”, będzie porównywalne. Podobnie ideały demokratyczne czeskie (mieszczańskie) czy słowackie (chłopskie) lub rumuńskie. Marzenia narodowe o „wielkiej Polsce”, „wielkich Węgrzech”, „wielkiej Rumunii” okażą się wówczas albo nacjonalizmami ksenofobicznymi, albo otwarciem i współpracą regionalną i/lub europejską.

Istnieją olbrzymie różnice między krajami Europy Środkowej i jedynym wspólnym mianownikiem jest, według Kundery, jak widzieliśmy, nietrwałość historyczna ich losów. Ale wydaje się, że nie tylko - chodzi o zakorzenienie tych kultur w romantyzmie, myśli Herdera i przekonanie, że jedyną drogą samorealizacji pozostaje kultura, gleba duchowości. Drugą cechą wspólną jest pojawienie się specyficznej warstwy inteligencji, o której była już mowa.

Trzecią cechą wspólną Europy Środkowej jest obsesja tożsamości, pytanie: „kim naprawdę jesteśmy?”. Poszukiwanie tożsamości narodowej przyjmuje często formy quasi-religijne, wręcz mistyczne, i karmi duchowość niekoniecznie ortodoksyjną, ale bogatą i oryginalną, o szerokim zasięgu, jak w przypadku świętych i filozofów czy poetów regionu: św. Jan Paweł II, Edith Stein, Emmanuel Lévinas, Jan Patočka, Leszek Kołakowski, Sándor Márai, Mircea Eliade, Józef Tischner, Zbigniew Herbert... Nie mówiąc o heroldach Europy Środkowej, takich jak Miłosz, Kundera, Bibó czy Szücs...

Charakterystyczne jest, iż w Stanach Zjednoczonych na przykład określenie „pisarza Europy Środkowej” obejmuje zazwyczaj pisarzy pochodzenia żydowskiego, takich jak Franz Kafka, Robert Musil, Joseph Roth, Danilo Kiš, Bruno Schulz, Imré Kertesz, bracia Isaac Bashevis i Israël Joshua Singer, Georges 
Konrád, Marek Edelman i nawet Saul Bellow (Kanadyjczyk pochodzenia żydowsko-rosyjskiego)... Istotnie, obecność Żydów jest cechą wspólną Europy Środkowej. (Charakterystyczne, że dotyczy również ich nieobecności po Holocauście oraz całego dyskursu o zachowaniu pamięci o kulturze żydowskiej).

Wspólnym mianownikiem tych pisarzy, pomimo różnic stylu i tematów, jest środowisko miejskie, gdzie rozgrywają się ich powieści, podczas gdy u innych pisarzy regionu, zakorzenionych etnicznie w swych krajach, temat życia na wsi jest obecny silnie, właściwie dominujący. Na przykład prąd literatury węgierskiej zwanej „ludową” (,populistyczną”, od łac. populus = lud), opisujący życie chłopów, rozwinął się na Węgrzech w latach trzydziestych XX wieku. Długo w regionie utrzymywała się też identyfikacja dobra z życiem na wsi, podczas gdy miasto symbolizowało piekło cywilizacji (Polska, Rumunia, Słowacja, Ukraina, Węgry...) ${ }^{29}$. Historycznie i socjologicznie Żydzi (obok Niemców) spełniali w regionie rolę klasy kupieckiej i burżuazji. Ale pomimo zróżnicowania miejsc akcji sprawa tożsamości indywidualnej i narodowej, czy to na wsi, czy w miastach, pozostawała dla wszystkich centralna. Pogłębiona była często przez wymiar historyczny i miejsce wspólnoty żydowskiej w uprzednich wiekach (Isaac B. Singer).

Przeszłość, pamięć i stosunek życia środkowoeuropejskiego do społeczeństw mieszczańskich Zachodu oraz liberalizmu kojarzonego z nowoczesnością były tematami równie ważnymi jak tożsamość narodowa. Stało się to obsesją po 2004 roku, po wejściu tych krajów do Unii Europejskiej. Partie prawicy nacjonalistycznej i populistycznej prowadziły specyficzną politykę historyczną, licząc na rekonstrukcję mitów narodowych, obrazów chwały przeszłości historycznej nawet odległej w czasie, i związków z tradycją chrześcijańską. Było to zmienne zależnie od kraju i okresów, ale kwestia odrębnej tożsamości narodowej stała się w gruncie rzeczy wszędzie rodzajem natręctwa. Mogą świadczyć o tym na przykład spory ukraińskie wokół bohaterów - gdyż naród nie może żyć bez bohaterów, bohaterów w tej części Europy przeważnie typu wojownika ${ }^{30}-$ nawet jeśli byli skompromitowani przez współpracę z nazistami i uczestnictwo w ludobójstwie. Warto w tym miejscu przypomnieć, że Węgrzy po utworzeniu podwójnej monarchii Austro-Węgier zbudowali w 1896 roku w Budapeszcie plac Bohaterów (Hösök tere), by uczcić 1000 lat od przybycia walecznych plemion węgierskich do basenu Karpat. To tam następnie odbywały się ważne ceremonie narodowe, jak solenny hołd złożony Imre Nagyowi, męczennikowi powstania w Budapeszcie w 1956 roku, potajemnie osądzonemu, skazanemu

29 Por. J. Jedlicki, Jakiej cywilizacji Polacy potrzebują. Studia z dziejów idei i wyobraźni XIX wieku, Warszawa 1988; tenże, Świat zwyrodniaty. Lęki i wyroki krytyków nowoczesności, Warszawa 2000.

30 Rozróżnienie pomiędzy rozmaitymi typami bohatera: twórcy państwa, legislatora, wojownika, wielkiego człowieka... za: P. Centlivre, D. Fabre, F. Zonabed, La Fabrique des héros, Paris 1999. Wydaje się, że w okresie nowoczesnym w Europie Środkowo-Wschodniej dominowały figury wojowników i poetów. 
i straconemu przez Sowietów w czerwcu 1958 roku (a w 2018 r. przeniesionemu gdzie indziej $\left.{ }^{31}\right)$.

U podstaw sprawy tożsamości w krajach Europy Środkowej znajduje się kwestia relacji między instytucjami scentralizowanego i silnego państwa a antyinstytucjonalną tradycją romantyczną, z której wyszły wszak kultury regionu. Sprawa wielce skomplikowana za naszych dni, od czasu wejścia krajów do Unii Europejskiej z jej regułami, prawem i dyrektywami. To kwestia, od której zależy przyszłość regionu i jego tradycji tożsamościowych.

Trzeba dodać jeszcze jeden wymiar. Dyskurs Zachodu, to znaczy cywilizacji w sensie Huntingtona, nie jest jasny. Ani Unii Europejskiej, ani Stanów Zjednoczonych, potęgi amerykanizacji konsumerystycznej, jak zapowiadał to Miłosz w Widzeniach nad Zatoką San Francisco. Należałoby dodać pytanie o współczesną tożsamość europejską: zdecydowana przewaga tożsamości syntagmatycznej (idem) krajów dawnego Zachodu i odradzanie się aspiracji do tożsamości paradygmatycznej (ipse) w Europie Środkowej piętnowane są jako regres i powrót do esencjalizmu. Może nie o typ tożsamości chodzi, a o jej ewolucję ku nowoczesności? Jak rozumianej?

Niejasność tożsamościową Zachodu ujawniają kryzysy: wahania w sprawie pomocy Ukrainie, rozdartej pomiędzy dwie cywilizacje (co Huntington przewidywał od lat), strategia w stosunku do Państwa Islamskiego czy kryzys grecki... (przykłady zmieniają się). Ostatni kryzys dotyczy migracji i (zaraz potem) systemów prawnych.

Transformacje po upadku komunizmu w 1989 roku wskazują wspólne cechy regionu pomimo różnic. Po upojeniu pluralizacją, przemianami kapitalistycznymi, ale również po traumie bezrobocia i emigracji ekonomicznej nadszedł czas dochodzenia do siebie, zwłaszcza w tym, co dotyczy młodych, którzy nigdy nie znali komunizmu. Jedyny sens życia zredukowany do walki o sukces rozbudził nieufność do liberalizmu proceduralnego. Pragnienie odzyskania dumy narodowej zrodziło, zwłaszcza w Polsce i na Węgrzech - ,politykę historyczną" i wolę niezależności moralnej, podtrzymywaną przez Kościół, jak też opozycję w stosunku do modeli liberalnych obyczajów. Perspektywa małżeństw homoseksualnych, usuwania ciąży i prokreacji in vitro, odrzucane przez Kościól, spowodowały instrumentalizację, pobudzanie dystansowania się do Zachodu i powrót do ortodoksyjnej tradycji religijnej. Kryzys migracji wzmocnił poczucie odrzucania nowoczesności „po zachodniemu”. Jednocześnie solidarność z Ukrainą, przypominającą Polakom po Majdanie walki Solidarności, jak też myśl polityczna odziedziczona po „Kulturze” paryskiej i Giedroyciu pozwoliły na zgrupowanie partnerów politycznych wokół doktryny ULB (Ukraina - Litwa - Białoruś), realizowanej do 2015 roku i zwycięstwa wyborczego PIS; mniej w wypadku rządów Victora Orbána na Węgrzech, ale w mniejszym

31 To Victor Orbán zdecydował, że nie można gloryfikować byłego komunisty (chociaż męczennika). 
stopniu również $\mathrm{w}$ innych krajach regionu. Ideał solidarności środkowoeuropejskiej rozbudził pamięć Europy Jagiellonów, Habsburgów i dawnych koncepcji „międzymorza”. Marzenia o regionie autonomicznym kulturowo i etnicznie, u źródeł Inicjatywy Trójmorza - Bałtyku, Adriatyku i Morza Czarnego. $\mathrm{Na}$ razie jest to tylko projekt (mimo zapowiedzi budowy Via Carpatia), ale stymulujący politykę populistyczną odnoszącą sukcesy w wyborach w Polsce i na Węgrzech. Pojawiła się też wola tworzenia autokracji. Społeczeństwo obywatelskie, o tradycjach walki z komunizmem mocno się tym tendencjom opiera. Ale nic nie jest jak na razie rozegrane.

Nie wszystko bowiem rozgrywa się na poziomie dyskursu i narracji. Przynależność wyraża się silnie na poziomie zachowań kulturowych, rytuałów, interakcji, które nadają strukturę głębokiej afektywności relacjonalnej każdej kulturze. Obecny kryzys w Unii Europejskiej wyjawia odwrócenie się biegunów. Jak stwierdza politolog francuski pochodzenia czeskiego, w krajach Europy Środkowej, gdzie bito się o wolność w imię praw człowieka, „zachowano koncepcję niemiecką etniczno-kulturową narodu, ekstrapolowaną na plan europejski, i to w momencie, gdy Niemcy przyjęły wizję Europy opartą na wartościach uniwersalnych praw człowieka”32. Bipolarność oświecenia i romantyzmu została więc zachowana, ale nastąpiła zamiana biegunów. Na jak długo?

\section{Bibliografia}

Aleksiun N., Beauvois D., Ducreux M.-É., Kłoczowski J., Samsonowicz H., Anderson B., L'imaginaire national: réflexions sur l'origine et l'essor du nationalisme, Paris 1996.

Bibó I., Misère des petits Etats d'Europe de l'Est, Paris 1993.

Brzozowski S., Idee, Kraków 1990.

Centlivre P., Fabre D., Zonabed F., La Fabrique des héros, Paris 1999.

Culture et identité en Europe Centrale. Canons littéraires et visions de l'Histoire, red.

M. Masłowski, D. Francfort, P. Gradvohl, Paris-Brno 2011.

Deutsch K., Nationalism and Social Communication, Cambridge 1953.

Dissidences, red. Ch. Delsol, M. Masłowski, J. Nowicki, Paris 2005.

Dzieje inteligencji polskiej do roku 1918, red. J. Jedlicki, t. 1: Narodziny inteligen-

cji 1750-1831, red. M. Janowski, t. 2: Btędne koto 1832-1864, red. J. Jedlicki,

t. 3: Inteligencja na rozdrożach 1864-1918, red. M. Micińska, Warszawa 2008.

Finkelkraut A., L'ingratitude: conversation sur notre temps, Paris 1999.

Fragments d'Europe. Atlas de l'Europe Médiane et Orientale, 260 map, red. M. Foucher, Paris 1993.

32 J. Rupnik, Il y a des courants populistes ailleurs, mais en Europe centrale, ils sont au pouvoir [„Prądy populistyczne istnieją też gdzie indziej, ale w Europie Środkowej są u władzy”], „Le Monde”, 8-9.05.2016. 
Galmiche X., Europa pachnaca partykularyzmem? Nowe Abdery w Europie Środkowej albo przyzwolenie na pospolitość, tłum. M. Chmurski, „Przegląd Filozoficzno-Literacki” 2011, nr 2, zeszyt monograficzny: Modernizm(y) Europy Środkowej, red. E. Paczoska, M. Chmurski.

Galmiche X., Villes multiculturelles en Europe centrale. Lieux communs de la multiculturalité urbaine en Europe centrale, „Cultures d'Europe centrale” 2009, nr 8.

Gellner E., Nations et nationalisme, Paris 1989.

Goszczyńska J., Mit Janosika w folklorze i literaturze stowackiej XIX wieku, Warszawa 2001.

Halecki O., The Borderlands of Western Civilization. A History of East Central Europe, New York 1952.

Halecki O., East Central Europe in Postwar Organization, Philadelphia 1943.

Halecki O., The Limits and Divisions of European History, London-New York 1950; tłum. pol.: tenże, Historia Europy - jej granice i podziaty, tłum. J.M. Kłoczowski, Lublin 1994.

Havel V., Sita bezsilnych, tłum. P. Godlewski [w:] Hrabal, Kundera, Havel... Antologia czeskiego eseju, oprac. J. Baluch, Kraków 2001.

Histoire des idées politiques en Europe centrale, red. Ch. Delsol, M. Masłowski, Paris 1998.

Hroch M., Mate narody Europy. Perspektywa historyczna, ttum. G. Pańko, Wroctaw 2003.

Hroch M., Social Preconditions of National Revival in Europe. A Comparative Analysis of the Social Composition of Patriotic Groups among the Smaller European Nations, New York 1999.

Huntington S.P., The Clash of Civilization and the Remaking of World Order, New York 1996; tłum. pol.: tenże, Zderzenie cywilizacji i nowy ksztatt tadu światowego, tłum. H. Jankowska, Poznań 2018.

Jan Paweł II, Przemówienie wygtoszone w siedzibie UNESCO (2 czerwca 1980), http://domjp2.pl/pl/article/przemowienie-wygloszone-w-siedzibie-unesco-jan-pawel-ii-paryz-2-czerwca-1980\%5B2000328\%5D.html, dostęp: 6.09.2019.

Jedlicki J., Autocréation de l'intelligentsia [w:] Mythes et symboles politiques en Europe Centrale, oprac. Ch. Delsol, M. Masłowski, J. Nowicki, Paris 2002.

Jedlicki J., Jakiej cywilizacji Polacy potrzebuja. Studia z dziejów idei i wyobraźni XIX wieku, Warszawa 1988.

Jedlicki J., Świat zwyrodniaty. Lęki i wyroki krytyków nowoczesności, Warszawa 2000.

Kitzwalter T., O nowoczesności narodu. Przypadek polski, Warszawa 1999.

Kitzwalter T., „Zachód porwany... ”, „Kwartalnik Historyczny” 2013, nr 4.

Kłoczowski J., Mtodsza Europa. Europa Środkowo-Wschodnia w kregu cywilizacji chrześcijańskiej średniowiecza, Warszawa 1998.

Kłoskowska A., Kultury narodowe u korzeni, Warszawa 1996.

Kołakowski L., Kaptan i btazen, „Twórczość” 1959, z. 10; przedruk [w:] tegoż, Nasza wesota apokalipsa, Kraków 2010. 
Konràd G., L’Antipolitique, Paryż 1987.

Kostomarow M., Knyha buttia ukrajinśkoho narodu, (1846 przy prawdopodobnej współpracy Szewczenki) Kijów 1991.

Kroutvor J., Středni Evropa: anekdota a dějiny, „Svědectvī”, Paris 2001, nr 63 (wersja skrócona: 1981); wersja kompletna [w:] tegoż, Potiže s dějinami, Praha 1990 (ostatnie wydanie w samizdacie 1988); tłum. pol.: tenże, Europa Środkowa: anegdota i historia, tłum. J. Stachowski, Izabelin 1998.

Kundera M., L'ignorance, Paris 2000.

Kundera M., Le Rideau, Paris 2005; tłum. pol.: tenże, Zastona. Esej w siedmiu częściach, tłum. M. Bieńczyk, Warszawa 2006.

Kundera M., Les testaments trahis, Paris 1993; tłum. pol.: tenże, Zdradzone testamenty, tłum. M. Bieńczyk, Warszawa 1996.

Kundera M., Zachód porwany albo tragedia Europy Środkowej, tłum. M.L., „Zeszyty Literackie” 1984, z. 5; tłum. ang.: The Tragedy of Central Europe, „New York Review of Books", 26.04.1984.

Le Rider J., La Mitteleuropa, Paris 1994.

Lubac H. de, La postérité spirituelle de Joachim de Flore, t. 2: de Saint Simon à nos jours, Paris 1981.

Luciani G., Le livre de la genèse du peuple ukrainien, Paris 1956.

Luciani G., La société des slaves unis, Paris 1963.

Magocsi P.R., Historical Atlas of East Central Europe, wyd. 1, Seattle 1993.

Magris C., Danubio, Milano 1986; tłum. franc.: tenże, Danube, Paris 1988; tłum. pol.: Dunaj, tłum. A. Osmólska-Mętrak, J. Ugniewska, Warszawa 2004.

Masaryk T.G., Česká otázka: snahy a tužby národního obrození, Praha 1969.

Masaryk T.G., La Nouvelle Europe, Paris 2002.

Masłowski M., Etyka i metafizyka. Perspektywa transcendencji poziomej we wspótczesnej kulturze polskiej, Warszawa 2011.

Masłowski M., Etyzacja polityki - naczelna idea polskiego romantyzmu [w:] tegoż, Problemy tożsamości. Szkice mickiewiczowskie i (post)romantyczne, Lublin 2006.

Masłowski M., Gest, symbol i rytuaty polskiego teatru romantycznego, Warszawa 1998.

Masłowski M., „Inna Europa”, „Europa porwana”, Europa Środkowo-Wschodnia... Tożsamość kulturowa i paradygmat romantyczny, tłum. M. Nicińska, „Przegląd Filozoficzno-Literacki” 2013, nr 1-2, zeszyt monograficzny: $\operatorname{Modernizm(y)~Eu-~}$ ropy Środkowo-Wschodniej.

Masłowski M., „Pomnik Mickiewicza w Warszawie” [w:] Stawa z dowcipu sama wiecznie stoi... Prace oflarowane Pani Profesor Alinie Nowickiej-Jeżowej z okazji pięćdziesięciolecia pracy naukowej, red. M. Hanusiewicz-Lavallée, W. Pawlak, Lublin 2018.

Meinecke F., Weltbürgertum und Nationalstaat: Studien zur Genesis des deutschen Nationalstaates, München 1911. 
Michnik A., „Le Nouvel évolutionnisme” [w:] 1956, Varsovie-Budapest, red. P. Kende, K. Pomian, Paris 1978; przedruk [w:] tegoż, Penser la Pologne. Morale et politique de la résistance, Paris 1983.

Michnik A., Takie czasy... Rzecz o kompromisie, Londyn 1985.

Miłosz C., Rodzinna Europa, Paryż 1959.

Mochnacki M., O literaturze polskiej w wieku dziewiętnastym, oprac. Z. Skibiński, Łódź 1985.

Mythes et symboles politiques en Europe Centrale, red. Ch. Delsol, M. Masłowski, J. Nowicki, Paris 2002.

Norwid C.K., Niewola [w:] tegoż, Pisma wszystkie, wyd. J.W. Gomulicki, Warszawa 1970-1971, t. 3.

Norwid C.K., Promethidion [w:] tegoż, Dzieta wszystkie, t. 4: Poematy 2, Lublin 2011.

Pomian K., Europe centrale - Mitteleuropa, „Revue germanique internationale” 1994, nr 1.

Ricœur P., La métaphore vive, Paris 1975.

Ricœur P., Soi-même comme un autre, Paris 1990; wyd. pol.: O sobie samym jako innym, tłum. B. Chełstowski, Warszawa 2003.

Ricœur P., Temps et récit, t. 1-3, Paris 1983-1985; tłum. pol.: tenże, Pamięć, historia, zapomnienie, tłum. J. Margański, Kraków 2006.

Rupnik J., Il y a des courants populistes ailleurs, mais en Europe centrale, ils sont au pouvoir, „Le Monde”, 8-9.05.2016.

Rupnik J., L'autre Europe, crise et fin du communisme, Paris 1993.

Sellier A. i J., Atlas des peuples d'Europe centrale, Paris 1991.

Snyder T., The Reconstruction of Nations: Poland, Ukraine, Lithuania, Belarus, 15691999, New Haven 2003; tłum. pol.: tenże, Rekonstrukcja narodów. Polska, Ukraina, Litwa, Biatoruś 1569-1999, ttum. M. Pietrzak-Merta, Sejny 2006. Szporluk R., Communism and Nationalism. Karl Marx versus Friedrich List, New York-Oxford 1988.

Szücs J., Les trois Europes, Paris 1985; tłum. ang. 1983; tłum. pol.: tenże, Trzy Europy, tłum. J.M. Kłoczowski, Lublin 1995.

Walicki A., Naród, nacjonalizm, patriotyzm, Kraków 2009.

Walicki A., Philosophy and Romantic Nationalism. The Case of Poland, Notre Dame 1994.

Walicki A., Polska - naród - Europa [w:] tegoż, Polskie zmagania z wolnościa widziane z boku, Kraków 2000.

Wandycz P.S., The Price of Freedom. A History of East Central Europe from the Middle Age to the Present, London-New York 1992; tłum. pol.: Cena wolnosici. Historia Europy Środkowo-Wschodniej od średniowiecza do wspótczesności, thum. T. Wyrozumski, Kraków 1995.

Wheelwright Ph., Metaphor and Reality, Bloomington 1962. 